
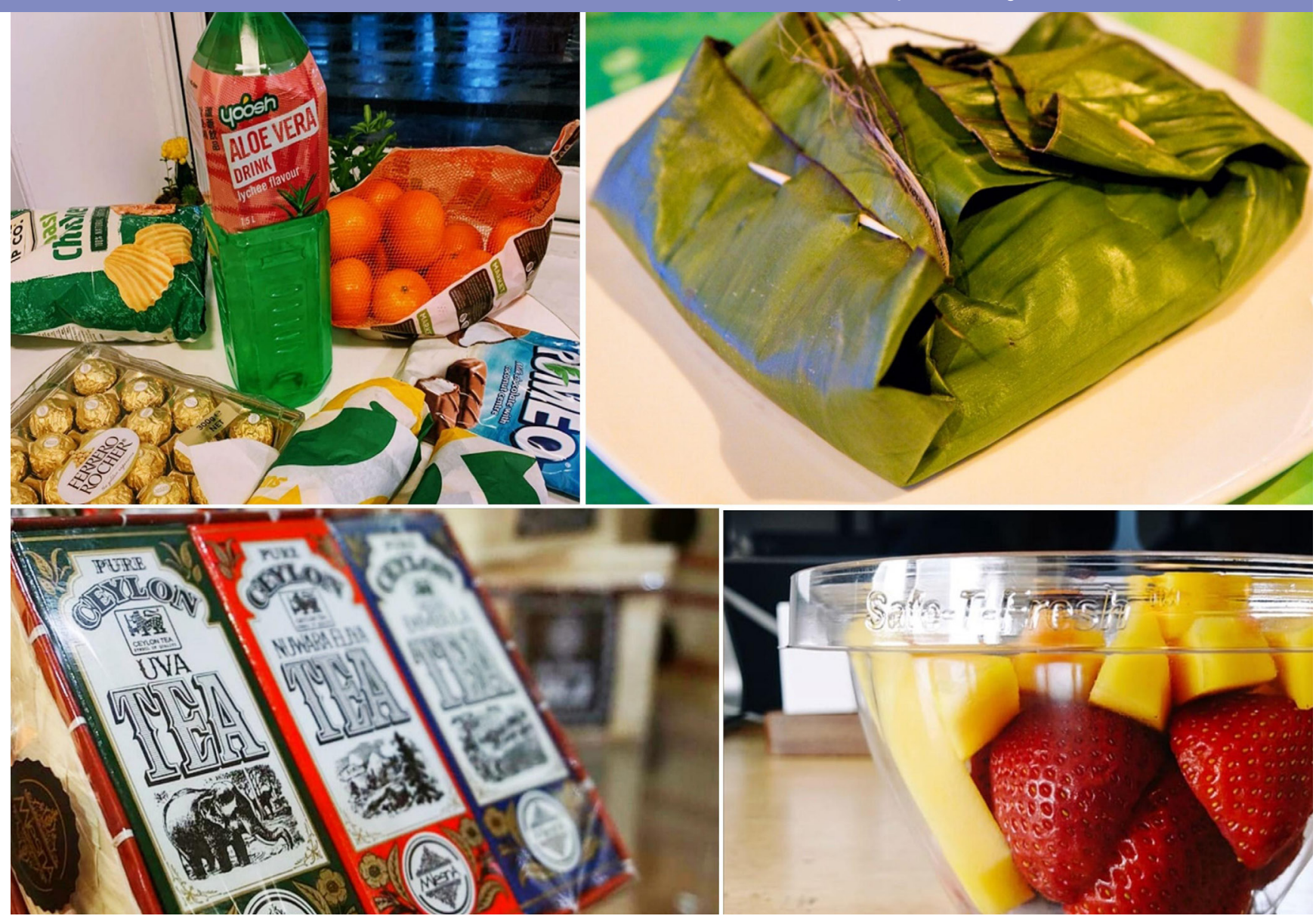

\title{
LIFE CYCLE THINKING FOR PACKAGING
}

Unsustainable packaging practices are one of the leading problems in today's world, leading to unnecessary resource consumption, increased waste generation, environmental pollution, and an overall negative impact on ecosystems. Global statistics show that 8 million metric tons of plastic ends up in the oceans every year. It has been estimated that approximately $79 \%$ of plastic produced since 1950 has been sent to landfills or otherwise released to the environment. With the current trends, the United Nations predicts that the plastic content will overweigh the fish in the ocean by 2050 [1].

Plastics used for food packaging accounts for approximately $42 \%$ of the global plastic production, and only $5 \%$ of these plastics is recycled [2]. Packaging waste accounts for $30 \%-35 \%$ of municipal solid waste in industrialized countries and food packaging contributes over $60 \%$ of the packaging waste [3]. Food packaging has multiple purposes including containing, marketing, protecting, and preserving food while also communicating essential 
information to the consumers. Unnecessary plastic or other material usage can be seen in packaging for various applications, due to various reasons including aesthetics, poor strength calculation etc. The environmental burden created by plastic food packaging can thus be reduced by improving food packaging designs, providing streamlined guidelines for sustainable packaging, and imposing standards on the food packaging industry.

In the waste management hierarchy, replacement and reduction are identified as proactive strategies for waste prevention and minimisation while reuse, recycle and recovery are categorised as reactive strategies for impact mitigation after the waste is generated. Since food packaging is normally associated with food residues, cleaning is essential which creates an extra burden for reuse and recycling [3]. Thus, proactive measures are preferred. The recent approaches of sustainable food packaging focus on mitigating the overall impact on the environment by using the optimum amount of material while maintaining the other essential functions of packaging [1]. Various mandatory and voluntary policies and initiatives have been adopted across the world to ensure that the packaging industry follows acceptable sustainability standards.

The existing packaging policies in Sri Lanka focus on restricting material usage. Several progressive guidelines and policies have been introduced during the recent times, such as banning the lunch sheets and polythene less than 20 microns and lunch boxes made of expanded polystyrene. Yet, in addition to minimising material use, maximising water and energy efficiency, using recycled and renewable materials, minimising risks to ecosystems and human health during various life cycle stages, sourcing responsibly, and designing for transport, recovery, reuse, accessibility, and litter reduction have been identified as important strategies in sustainable packaging design. Therefore, a holistic framework based on life cycle thinking is clearly needed in order to truly mitigate the adverse impacts of packaging use, as the environmental impacts are not created merely due to higher material use.

Pollution due to the irresponsible disposal of polyethylene terephthalate (PET) bottles in particular is a major concern for Sri Lanka. PET has

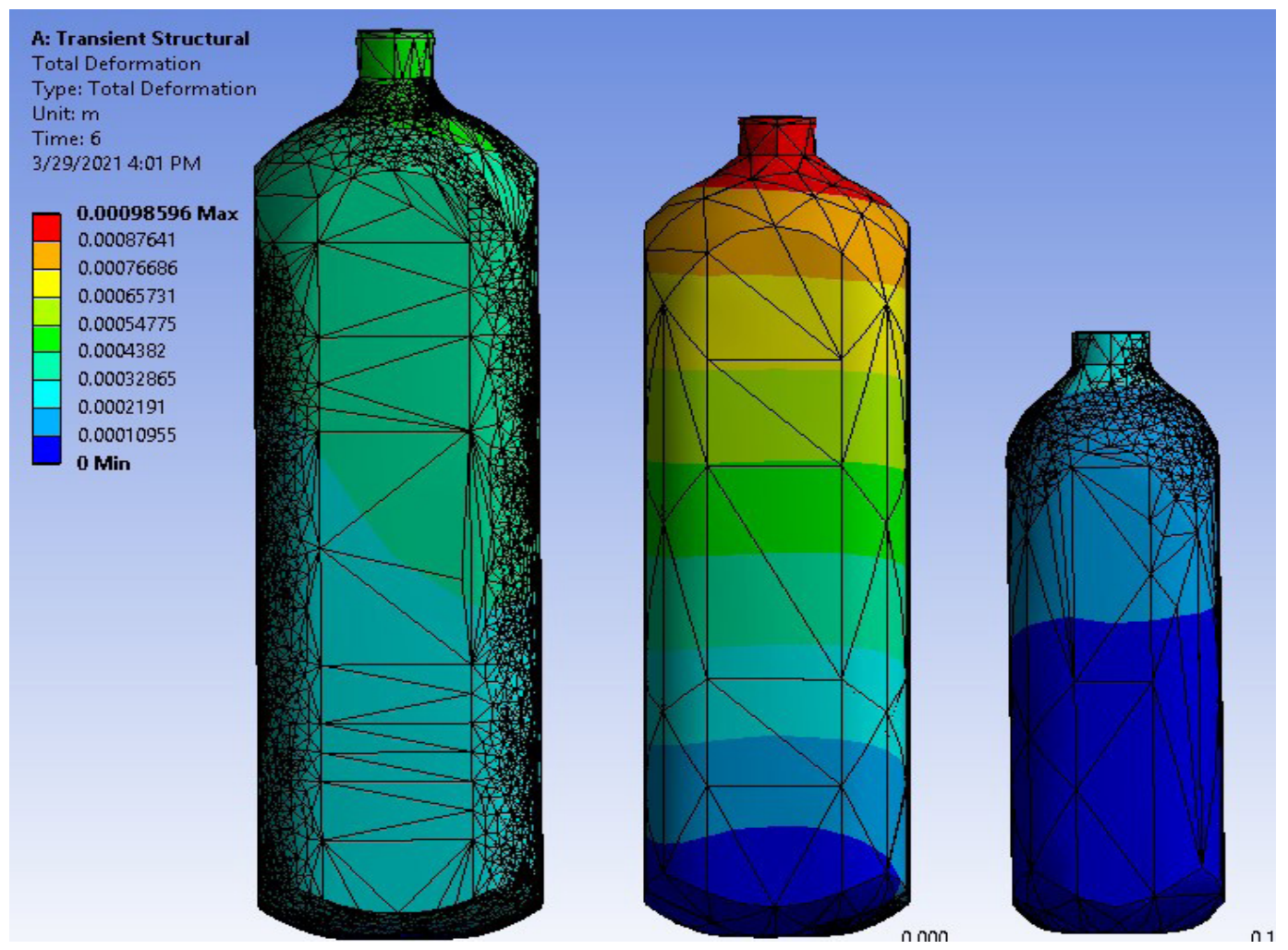

Figure 1: Deformation under calculated force 


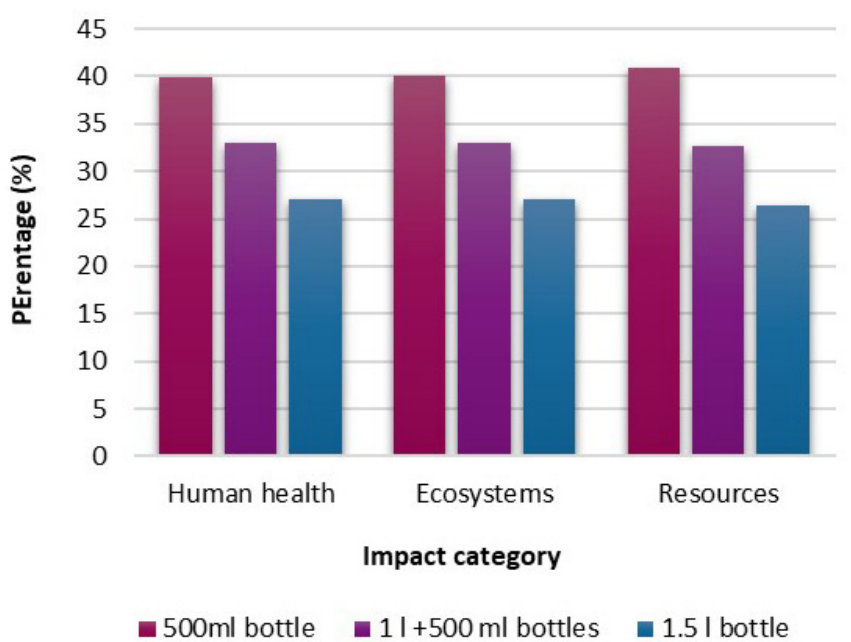

Figure 2: Impact assessment 0303for the case study of delivering 1.5 litres of water to consumers

a worse environmental performance than highdensity polyethylene (HDPE) and multilayer carton packs. It is identified that that the environmental impacts of PET bottles are highest during the assembly and the disposal phases. Redesigning PET bottles for sustainability needs to take structural, environmental, and economic considerations into account.

Considering this need, an initial study was carried out on developing a methodological framework to evaluate PET water bottles in terms of environmental and structural parameters, and to compare their performance based on life cycle thinking. SolidWorks 2017 was used to develop the $3 \mathrm{D}$ model and Ansys was used for computational finite element analysis. The structural performance of popular existing PET bottle designs and their stackability were analysed using the simulation results. The environmental impacts of the PET life cycle were evaluated on a cradle-to-gate basis using the SimaPro LCA software. The ReCiPe Endpoint $(\mathrm{H})$ LCIA method was used to identify the bottle design with the highest environmental impacts, for a functional unit of "packaging to deliver 1 litre of water". The results indicated that $500 \mathrm{ml}$ PET bottles have the highest and $1500 \mathrm{ml}$ bottles have the lowest negative environmental impacts from a life cycle perspective, when normalized for a specific volume of the product. However, there is a potential for eco-performance
"The results indicated that $500 \mathrm{ml}$ PET bottles have the highest and $1500 \mathrm{ml}$ bottles have the lowest negative environmental impacts from a life cycle perspective, when normalized for a specific volume of the product"

analysed designs, especially with the introduction of rib features and neck redesign.

These aspects need to be stringently studied and incorporated to design guidelines and policies that streamline the PET bottle production in the Sri Lankan market. A policy framework of this nature will be helpful for the food packaging designers, product manufacturers, and policymakers to make decisions on selecting the feasible and most ecofriendly packaging alternative.

\section{References}

[1] "UN's mission to keep plastics out of oceans and marine life," UN News, 2017. [Online]. Available: https://news.un.org/en/ story/2017/04/556132-feature-uns-mission-keep-plastics-outoceans-and-marine-life. [Accessed: 13-Feb-2021].

[2] B. Nemat, M. Razzaghi, K. Bolton, and K. Rousta, "The Potential of Food Packaging Attributes to Influence Consumers ' Decisions to Sort Waste," Sustain., vol. 12, no. 6, pp. 1-22, 2020.

[3] A. Tencati, S. Pogutz, B. Moda, M. Brambilla, and C. Cacia, "Prevention policies addressing packaging and packaging waste: Some emerging trends," Waste Manag., vol. 56, no. 2016, pp. 35-45, 2016.

\section{Article by}

\section{Sathindu Jagoda, Hirushie Karunathilake}

Janaka R. Gamage

Department of Mechanical Engineering, Faculty of Engineering, University of Moratuwa, Sri Lanka. 